\title{
Lei 10.639/03, formação docente e NEABs: a democratização do currículo como um desafio para a educação brasileira
}

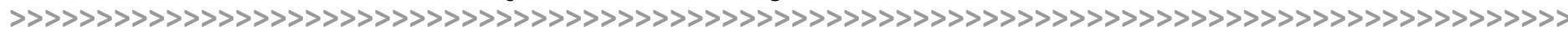

Marta Mariano Alves*

\section{Resumo:}

Este ensaio pretende apresentar uma reflexão sobre a Lei no 10.639/03 que inclui no currículo oficial da rede de ensino nacional a obrigatoriedade da temática história e cultura afro-brasileira; a formação docente; as Instituições de Educação Superior (IES) e os Núcleos de Estudos Afro-Brasileiros (NEABs) no processo de democratização do currículo da educação brasileira. Para esta reflexão inicialmente apresenta o histórico da Lei no 10.639/03 e a proposta de formação docente presente na legislação brasileira. Na sequência, tendo como referência a Lei 10.639/03, busca refletir a respeito da democratização do currículo como um desafio para a educação brasileira e para as IES e o papel dos NEABs na implementação da Lei no 10.639/03.

\section{Palavras-chave:}

Relações étnico-raciais. Lei 10.639/03. Formação docente. Democratização curricular. NEABs.

\begin{abstract}
:
This essay intends to present a reflection on the law n. 10.639/03, which includes a mandatory policy on the teaching of African-Brazilian Culture and history in the National education's official curriculum. Also, this reflection well include the teacher training; the Higher Education Institutions (Instituição de Educação Superior - IES); and the African-Brazilian Research Groups (Núcleos de Estudos Afro-Brasileiros - NEABs) in the democratization process of the Brazilian education's curriculum. In order to these ideas achieve first it is presented the history of law n. 10.639/03 and the proposed teacher training in the Brazilian legislation. Following that, the objective is to reflect on the curriculum democratization as a challenge for Brazilian education, and the role of NEABs in the implementation of law n. 10.639/03.
\end{abstract}

\section{Keywords:}

Ethnic-racial relations. Law 10.639/03. Teacher training. Curriculum democratization. NEABs.

\section{Lei 10.639/03 e a Formação docente}

No início dos anos 2000, surge no Brasil ações e intervenções que passarão a ser denominadas como políticas afirmativas. Segundo Gomes (2011, p. 113) a partir do final da década de 1990 as políticas afirmativas passam a ser consideradas como uma possibilidade na luta política do movimento negro brasileiro na perspectiva de ponderar a educação como um direito social e um espaço também de diversidade étnico-racial. Isto, conduzirá
* > Mestrado em Educação pela Univer sidade Federal do Rio Grande do Sul; . Especialização em Organização do TrabaIho Pedagógico (OTP) e em Educação das Relações Étnico-Raciais pela Universidade Federal do Paraná. Graduação em Pedagogia (Universidade Estadual do Oeste do Paraná/Universidade Federal do Paraná). Pedagoga na rede de ensino público da Secretaria de Estado da Educação do Paraná. E-mail: malves.ufrgs@gmail.com 
ao final dos anos de 1990 e inicio dos anos 2000 a ações por parte do Estado brasileiro, em consonância com reivindicações apresentadas pelo movimento negro brasileiro em direç̃o a criação de alternativas para atender alguns pontos de pauta presentes nestas reivindicações.

As políticas afirmativas e a demanda gerada pelo movimento negro brasileiro em busca de reparações e de ações compensatórias por um processo histórico de exploração tortura e assassinato da população negra, trazem implícito como essência uma luta histórica por garantia de direitos fundamentais e Direitos Humanos, como a dignidade, a saúde, a educação, a justiça, a alimentação, entre outras. Da mesma forma, é implícito no processo reivindicativo de políticas afirmativas e reparaçes que tem como foco un resgate histórico, uma luta pelo reconhecimento da contribuicão da população negra para a construção da sociedade e das riquezas da nação brasileira; associado a denúncia do conjunto de estratégias usadas contra esta população para colocá-la à margem de direito sociais e constitucionais. Entre estas estratégias contra a população negra, consta o impedimento no espaço educacional institucional do acesso a uma memória histórica positiva.

É neste cenário de reivindicações do movimento negro, no âmbito das políticas afirmativas, que surge um novo marco regulatório para a educacão brasileira por meio da Lei 10.639/03. A Lei 10.639/03 inclui na LBD 9394/96 o Artigo 26-A, que define a obrigatoriedade da temática "História e Cultura Afro-Brasileira e Africana" como conteúdo curricular na Educação Básica ofertada no território nacional brasileiro e conjuntamente inclui o Artigo 79-B que define como elemento do calendário escolar brasileiro o dia 20 de novembro como o Dia Nacional da Consciência Negra.

O processo embrionário da Lei 10.639/03 e das políticas afirmativas de âmbito nacional no Brasil é resultado da articulação entre as reivindicações do movimento negro brasileiro e a ação de representantes políticos que conduziram estas reivindicações para o debate no espaço do legislativo; permitindo com isto a apreciação destas reivindicações na Câmera Federal, no Senado Federal, bem como, no judiciário brasileiro. Em 1983 o projeto de Lei $\mathrm{n}^{\circ} 1.332$ do deputado federal Abdias Nascimento, fruto de reflexões em décadas anteriores junto ao movimento negro, mencionava a incorporação no currículo escolar e acadêmico de conteúdos posit descendentes no Brasil, organização e luta contra o racismo. No entanto, o projeto não foi aprovado e foi arquivado em 1989.

No ano de 1993 a Proposta de Emenda Constitucional, PEC no 008583-6, de autoria do deputado federal Florestan Fernandes, pleiteou o reconhecimento constitucional dos negros brasileiros. No discurso de Florestan Fernandes de defesa da PEC nº 008583-6/1993, estava presente o argumento de que, "[...] se quisermos possuir uma República democrática temos que atribuir ao negro como indivíduo e coletividade, um estatuto democrático. $\mathrm{O}$ negro tornou-se o teste número um da existência da universalidade e da consistência da democracia no Brasil" (FERNANDES; FERNANDES, 2010, p. 38). Posterior a Floresta Fernandes o projeto de Lei no 1.239 de 1995 (BRASIL, 1995), de autoria do deputado federal Paulo Paim, que foi retirado pelo autor e arquivado em 2002, apresentava en meio a suas propostas uma que indicava a reformulação curricular com foco na questão do negro brasileiro.

Em 1998 é apresentado pelo deputado federal Luiz Aberto, o Projeto de Lei no ${ }^{\circ} 4.567$ (BRASIL, 1998) que tinha como objetivo a criação do fundo nacional para financiament de ações afirmativas e apontava como um possível uso deste financiamento, entre outros, o apoio a iniciativas de defesa da cultura, memória e tradições africanas e afro-brasileira. Na sequência, o Projeto de Lei no 259 de março de 1999 (BRASIL, 1999) foi apresentado pelo deputado Ben-hur Ferreira e a deputada Esther Gross. O Projeto de Lei no 259 ap tramitar pelo Senado Federale a apresentača de alguns vetos constituirá a nossa atual Lei $10.639 / 03$.
Ao mencionar a Lei 10.639/03 é importante também lembrar do histórico do grupo étnico ao qual faz referência esta lei. Isto porque, o conhecimento histórico do que foi $o$ processo de escravização negra no Brasil permite o entendimento do tratamento desigual que recebeu a população negra e branca no território brasileiro. Um ponto de partida assimétrico, com um tratamento econômico, social, jurídico e educacional, diferenciado (BENTO, 2002; GRIN, 2009) e legitimados socialmente (ATTALI, 2003; REIS, 2007; SILVA, 2011; TAUNAY, 2001; MONSMA, 2016), pelo Estado (BERBEL, 2010; CASTRO, 1984; MALHEIRO, 1867) e por diversas religiões (MALHEIRO, 1867; ASSUNÇÃO, 2009, ATTALI, 2003; MOORE, 2012); que estruturou uma assimetria entre a população branca e negra brasileira colocando esta última em uma posição de marginalização histórica e social. Segundo Monsma (2016), até mesmo os imigrantes ao chegarem no Brasil, antes e após a abolição da escravatura (1888) acabaram por adaptar-se a um "habitus racial", manifesto em atitudes racistas e um posicionamento anti-negro, desenvolvido "pela experiência em um mundo social racializado" (MONSMA, 2016, p. 52).

É igualmente relevante lembrar do histórico de luta e resistência da população negra brasileira contra o processo de escravização, o seu encontro em uma variedade de momentos com a traição (SILVA, 2010) e a sua organização de combate ao racismo e a desigualdade que se estende até os dias atuais (REIS, 1986; ALBERTI; PEREIRA, 2007; PEREIRA; SILVA, 2009; PEREIRA, 2013; SANTOS, 2015).

A luta do movimento negro brasileiro para a democratização do currículo escolar com a inclusão neste espaço de conteúdos significativos relacionados à contribuição de outros segmentos da população para a construção da nação brasileira; é um processo histórico que antecede a Lei 10.639/03. Em 20 de novembro de 1995 é realizada em Brasília/Brasil a "Marcha Zumbi contra o racismo, pela igualdade e a vida". A Marcha, que contou com a participação aproximada de 30 mil pessoas, foi realizada na data que fazia referência aos 300 anos da morte de Zumbi do Palmares, com o objetivo de denunciar a difícil situação econômica, social e a falta de acesso a direitos constitucionais vivenciado pela população negra brasileira em função do racismo. A marcha foi recebida pelo Presidente da República, o qual foi entregue um "programa de superação do racismo e da desigualdade racial" Neste programa o tópico "Racismo e Escola" denuncia um modelo educacional brasileiro que atenta contra a dignidade humana e o racismo presente em conteúdos eurocêntricos e no item "III-Educação" do mesmo documento, é solicitado investimento na formação docente com o objetivo de prepará-lo para o trabalho com a diversidade racial.

Em 13 de maio de 1996 o Decreto no 1.904 , institui o primeiro Programa Nacional de Direitos Humanos (PNDH-1), que apresentará entre suas propostas de ação o estimulo para que "[.] livros didáticos enfatizem a história e as lutas do povo negro na construça do nosso país, eliminando estereótipos e discriminações" (BRASIL, 1996a). Posteriormente o Decreto $\mathrm{n}^{\circ} 4.229$, de 13 de maio de 2002 promulga o segundo Programa Nacional de Direitos Humanos (PNDH-2), que apresentará entre suas propostas de ação:

214. Apoiar o processo de revisão dos livros didáticos de modo a resgatar a histéria e a contribuiç̃o dos afrodescendentes para a construção da identidade naciont.

215. Promover um ensino fundado na tolerância, na paze no respeito à diferença, que contemple a diversidade cultural do país, incluindo o ensino sobre cultura e históri dos afrodescendentes (BRASIL, 2002a).

O terceiro Programa Nacional de Direitos Humanos (PNDH-3) entra em vigor com o Decreto nº 7.037, de 21 de dezembro de 2009 e define entre as ações: "c) Elabora programas de combate ao racismo institucionale estrutural implementando normas admipistrativas le (1) Asseguraro resgate da memória da populações negras, mediante a publicação da história de resistência e resgate de tradições das populações das diásporas" (BRASIL, 2009a) 
Segundo Gomes (2011, p. 113) é a partir do final dos anos 1990 que as demandas do movimento negro passam a declarar o acesso a educacão básica e superior como um direito social e consequentemente um espaço de direito à diversidade étnico-racial, intensificando nos anos seguintes a luta também no campo educacional.

A Lei 10.639/03 apresenta uma relação com ações de luta internacional contra o racismo, definidas no espaço da Organização das Nações Unidas (ONU) no ano de 2001, quando o movimento negro brasileiro levou suas reivindicações para o espaço da diplomacia internacional e segundo Silva (2011), as políticas públicas de ação afirmativa adotadas atualmente no Brasil, tiveram também a influência de reivindicações pautadas durante a Conferência Mundial de Durban:

Em boa medida, as posiçōes defendidas pelo Brasil em Durban, em 2001, foram definidas a partir de um intenso, futtfero e nem sempre facil dialogo entre o Governo e representantes do Movimento Negro brasileiro. Como consequência desse processo, passaram a ser implementadas no País políticas públicas de ação afirmativa que têm buscado promover uma mais ampla integração dos afrodescendentes a espaços educacionais e do serviço publico. Respaldadas na Constituição de 1988 e nos instrumentos internacionais de proteção dos direitos humanos, essas políticas são nẫo apenas necessárias, mas indispensáveis. Afinal, como assinalou recentemente Nav Pillay, Alta Comissária das Naç̃oes Unidas para os direitos humanos, em referência a população afrodescendente, 'nunca poderemos fazer justiça aos milhões de vítimas do preconceito e da intolerância - e a seus descendentes, que ainda enfrentam o legado da discriminação' (SILVA, 2011, p. 16-17)

A ONU não surge como consequência dos massacres, atrocidades e assassinatos sofridos por negros, indígenas e outros grupos étnicos que, durante os séculos que antecedem o ano de 1945 foram exterminados. Porém, transforma-se em mais um espaço para que estes grupos lutem em meio a conflitos e relações de poder, pelo reconhecimento do status de Seres Humanos. Uma dessas lutas teve como cenário a cidade de Durban na África do Sul em 2001, durante a III Conferência Mundial de combate ao Racismo, Discriminação Racial, Xenofobia e Intolerância Correlata e o resultado dos debates e negociações consta como orientação para os países membros na Declaração e Plano de Ação de Durban. No documento consta no programa de ação as seguintes orientações:

5. Solicita que os Estados, apoiados pela cooperação internacional, consideren positivamente a concentração de investimentos adicionais nos serviços de saúde, educação, saúde pública, energia elétrica, água potável e controle ambiental, bem como outras iniciativas de ações afirmativas ou de ações positivas, principalmente, nas comunidades de origem africana;

8. Exorta as instituições de financiamento e de desenvolvimento, os programa operacionais e as agências especializadas das Nações Unidas, de acordo com seu orçamentos ordinários e com os procedimentos de seus órgãos diretores a: [...] c) Desenvolver programas destinados aos afrodescendentes alocando recursos adicionais aos serviços de saúde, educação, moradia, energia elétrica, saneamento, medidas de controle ambiental e promover a igualdade de oportunidades no emprego, bem como em outras iniciativas de açôes afirmativas ou positivas;

11. Incentiva os Estados a identificarem os fatores que impedem o igual acesso e a presença eqüitativa de afrodescendentes em todos os níveis do setor público incluindo

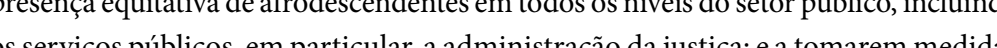
apropriada à remoc̃o dos obstáculos identificados e também a incentivar o setor pivado a promor o igla dos os níveis dentro de suas organizações

118. Insta as Nações Unidas, outras organizaçoess internacionais e regionais e os Estados a compensarem a minimização da contribuição da Africa para a historia do mundo e da civilização através do desenvolvimento e implementação de programas de pesquisa educaç̃ão e comunicação de massa abrangentes e específicos para disseminarem de forma ampla uma visão equilibrada e objetiva da importante e valiosa contribuição da África para a humanidade (ONU, 2001).

A leitura da Declaração e do Plano de Ação de Durban, especificamente dos itens "Africanos e Afrodescendentes" e "Educação e Medidas de sensibilização", permite o entendimento de que as políticas de ação afirmativas e ações governamentais adotadas no Brasil mantém uma consonância com algumas questões estabelecidas na III Conferência Mundial de Durban.

A observação da Lei 10.639/03 representa para a população negra brasileira, de forma implicita, $\mathrm{o}$ acesso ao direito à memória e à verdade e o compartilhar desta com a população brasileira. O que, adotando como referência o Programa Nacional de Direitos Humanos (PNDH-3) do Brasil, no eixo orientador VI, pode ser considerado como acesso à cidadania. O PNDH-3 a respeito desta concepção de cidadania declara que "[...] a investigação do passado é fundamental para a construção da cidadania. Estudar o passado, resgatar sua verdade e trazer à tona seus acontecimentos, caracterizam forma de tran missão de experiência histórica que é essencial para a constituição da memória individual e coletiva" (PNDH-3, 2009, p. 170).

O fato da Lei 10.639/03 indicar a inclusão no currículo escolar de conteúdo referente à participação e contribuição de parcelas da população até então tratadas de forma pejorativa ou excluídas do conteúdo curricular da Educação Básica, permite que esta lei seja interpretada como um direcionamento para a democratização do currículo da educação brasileira e igualmente, um incentivo às Instituições de Educação Superior (IES) para a estruturação de um processo de resgate da produção intelectual relacionada à população negra ou produzida por negros(as) com foco na contribuição desta população para as diversas áreas do conhecimento. O que é significativo no contexto educacional porque, segundo Cavalleiro (2006) é recente a presença de algumas temáticas relacionadas à população negra no espaço acadêmico universitário e a respeito disto ela declara que:

[...] apenas na segunda metade do século XX que, na perspectiva acadêmica, os trabalhos de Abdias Nascimento, Clóvis Moura, Florestan Fernandes, Lélia Gonzale Otavio Ianni, Roger Bastide, entre outros, sobre as condiçōes de vida da população negra no Brasil, fizeram contraponto as teorias de Silvio Romero, Oliveira Viana, José Veríssimo, Nina Rodrigues e Gilberto Freyre (CAVALLEIRO, 2006, p. 17).

Porém, com relação à Lei 10.639/03 Gomes (2011) afirma que “[...] a sua efetivação como política pública em educação vem percorrendo um caminho tenso e complexo no Brasil" (GOMES, 2011, p. 116) e a afirmação conduz a inferir que existe uma resistência na efetivação desta lei por parte dos que possuem relações de poder em um âmbito macro ou micro da educação brasileira, capaz de influenciar na implementação de uma legislação e impedir ou criar obstáculos a uma democratização curricular.

A educação no Brasil desde o período colonial apresenta referenciais de normatização, sejam elas instituídas por uma ordem religiosa (Companhia de Jesus), por uma perspectiva de ensino laico (Reforma Pombalina) ou pelas características específicas de cada uma das reformas educacionais, leis, decretos, resoluções e pareceres, posteriores as normatizações do período colonial . Desta forma, a legislação ou orientação oficial educacional brasileira desde a colônia e posteriormente no Império e na República fo regida por elementos diversos de normatização, de organização, de conteúdo curricular e de definição dos que teriam o direito ao acesso ao ambiente escolar. A exemplo, com relação ao direito de acesso a educação escolar no Brasil Império, temos o Decreto no 1.331-A de 17 de fevereiro de 1854, que proibia o acesso aos negros(as) escravizados(as) ao ambiente escolar (BRASIL, 1854) 
A existência de normatizações educacionais é algo habitual no contexto educacional das nações na atualidade, com algumas exceções em função de fatores diversos que possam impedir a definição de alguns referenciais comuns a serem observados em uma proposta de educação nacional. Ao examinar atentamente estas normatizações, além de uma proposta de organização da educação nacional com elementos como a estrutura; oferta; currículo ou orientação para a escolha dos conteúdos etc.; percebe-se um elemento tácito, que é uma concepção de educação, indivíduo e sociedade a ser compartilhada na estrutura educacional e na formação docente. É possível visualizar esta concepção ao realizar a análise ou comparação de uma legislação educacional ao longo de um período histórico. Por exemplo, quando examinamos alguns itens do Decreto nº 58.023, de 21 de março de 1966, que dispõe sobre a obrigatoriedade de um novo conteúdo curricular, que é a educação cívica, na educação ofertada em todo o país. Ao analisar o Decreto no 58.023 é possível concluir qual é a expectativa de indivíduo e de nação naquele contexto histórico:

Art. $2^{\circ} \mathrm{A}$ educação cívica visa a formar nos educandos e no povo em geral o sentimento de aprệco à Pátria, de respeito às instituiçōes, de fortalecimento da família, de obediência à Lei, de fidelidade no trabalho e de integração na comunidade, de tal forma que todos se tornem, em clima de liberdade e responsabilidade, de cooperação e solidariedade humanas, cidadãos sinceros, convictos e fiéis no cumprimento de seus deveres.

Art. $3^{\circ} \mathrm{A}$ formação cívica processa-se obrigatòriamente na escola, como prática educativa, mediante atitude freqüentes que lhe assegurem a continuidade e contribuam para a consolidação dos hábitos e ideais que ela colima. Deve ser praticada em todos os graus de ensino e ser preocupação dos professôres em geral e, especialmente, daqueles que, em virtude de suas áreas de ensino, tenham com ela conexão, como linguagem, geografia, história, música, educação física e desportos, artes plásticas, artes industriais, teatro escolar, recreação (BRASIL, 1966).

Na mesma linha de raciocínio, porém em direção a outro pólo, o Decreto nº 6.75 de 29 de janeiro de 2009, que apresenta como conteúdo a Política Nacional de Formação de Profissionais do Magistério da Educação Básica e onde constam elementos norteadores da formação docente, é possível observar nos princípios desta formação a relação entre a intencionalidade de educação e uma perspectiva de nação, nas seguintes definições:

Art. $2^{\circ}$ - São princípios da Política Nacional de Formação de Profissionais do Magistério da Educação Básica: [...]

II - a formação dos profissionais do magistério como compromisso com um projeto social, político e ético que contribua para a consolidação de uma nação soberan democrática, justa, inclusiva e que promova a emancipação dos indivíduos e grupos sociais; [...]

Art. 3- São objetivos da Política Nacional de Formação de Profissionais do Magistério da Educação Básica: [...]

VIII - promover a formação de professores na perspectiva da educação integral, dos direitos humanos, da sustentabilidade ambiental e das relaçoes etnico-raciais, con vistas à construção de ambiente escolar inclusivo e cooperativo (BRASIL, 2009b).

O exame dos artigos mencionados do Decreto $\mathrm{n}^{\circ} 6.755 / 09$ evidenciam a manifestação de uma intencionalidade com relação aos caminhos a serem trilhados no processo de formação docente e a relação desta, com uma perspectiva de educação nacional, de nação, indivíduos e sociedade, diferente da presente no Decreto n ${ }^{\circ} 58.023 / 66$. Em 09 de maio de 2016 o Decreto no 6.755/09 será substituído pelo Decreto n⿳ 8.752 (BRASIL, 2016), porém nos artigos mencionados anteriormente, com poucas alterações na redação, manterá o princípios expostos no Artigo $2^{\circ}$, inciso II e Artigo $3^{\circ}$, inciso VIII, respectivamente no Artigo $2^{\circ}$, inciso I e Artigo $3^{\circ}$, inciso VI.
No nosso contexto educacional brasileiro atual a LDB 9394/96 (Artigo 62) prevê que a formação inicial do docente da Educação Básica deve ser realizada em cursos de licenciatura de graduação ofertados pelas IES. O exercício da profissão docente com formação de nível médio apenas é permitido pela LDB 9394/96 (BRASIL, 1996b) na Educação Infantil e nas quatro primeiras séries do Ensino Fundamental. Consequentemente, pela previsão da legislação educacional vigente a formação inicial do docente concentra-se majoritariamente nos cursos de licenciatura ofertados pelas IES.

Quanto a formação continuada do docente, a LDB 9394/96 (Artigo 67, inciso V) declara que o professor tem direito a um "[...] período reservado a estudos, planejamento e avaliação, inclú́do na carga de trabalho". E ainda referente a formação continuada a Resolução do Ministério da Educação $\mathrm{CNE} / \mathrm{CEB} n^{\circ} 2$, de 28 de maio de 2009, indica que nos planos de carreira docente deve ser assegurado pelo sistema ao qual o docente tem vinculo funcional, ou por meio da colaboração com outros sistemas de ensino, "[...] a oferta de programas permanentes e regulares de formação continuada para aperfeiçoamento profissional, inclusive em nível de pós-graduação" (BRASIL, 2009c, Artigo 5, inciso XII), bem como "[...] utilizar as horas de trabalho pedagógicas coletivas como momento de formação do profissional da educação" (BRASIL, 2009c, Artigo 5º inciso XIII).

No ano de 2015, no dia $1^{\circ}$ de julho, foi promulgada pelo Ministério da Educação a Resolução n ${ }^{\circ} 2 \mathrm{CNE} / \mathrm{CP}$, que traz em seu texto a definição das diretrizes para a formação inicial e continuada nos cursos de licenciatura das IES. A Resolução (Artigo $3^{\circ}$, Parágrafo $5^{\circ}$, inciso II) reafirma a intencionalidade da educação associada a um projeto de nação como princípios da formação docente inicial e continuada:

II - a formação dos profissionais do magistério (formadores e estudantes) como compromisso com projeto social, político e ético que contribua para a consolidação de uma nação soberana, democrática, justa, inclusiva e que promova a emancipação dos individuos e grupos sociais, atenta ao reconhecimento e à valorização e, portanto, contrária a toda forma de discriminação (BRASIL, 2015).

A Resolução no 2/2015 CNE/CP também considera que o projeto de Formação de Profissionais do Magistério da Educação Básica deve contemplar, “[...] as questões socioambientais, éticas, estéticas e relativas à diversidade étnico-racial, de gênero, sexual, religiosa, de faixa geracional e sociocultural como princípios de equidade" (BRASIL, 2015, p. 5). O que instiga novamente a reflexão a respeito da inclusão da Lei 10.639/03 no processo de formação docente inicial e continuada, no âmbito das licenciaturas das IES, pelo motivo de que, a inclusão do conteúdo previsto na Lei 10.639/03 é um mecanismo para garantir ao discente na licenciatura o acesso aos conteúdos curriculares que permitirão o adequado exercício profissional docente no território nacional, a partir do que é exigido atualmente pela legislação educacional com relação ao conteúdo previsto na Lei 10.639/03. Conteúdo este que é solicitado como conhecimento necessário ao docente para atuar em sala no Parecer CNE/CP no 03 de 10 de março de 2004; Resolução CNE/CP no 1 de 17 de junho de 2004; Parecer CNE/CP n 05 de 13 de dezembro de 2005 (BRASIL, 2005); Decreto ${ }^{\circ}$ 6.755 de 29 de janeiro de 2009; Lei Federal no 12.288 de 20 de julho de 2010 (BRASIL, 2010a); Parecer CNE/CEB nº 5 de 4 de maio de 2011; Resolução CNE/CEB n ${ }^{\circ} 02$ de 30 de janeiro de 2012 (BRASIL, 2012b); Lei no 13.005 de 25 de junho de 2014 (BRASIL, 2014) e igualmente nas Diretrizes Curriculares Nacionais para a Educação Infantil (Resolução CNE/CEB n ${ }^{\circ}$ 5/2009, no Art. 8 8 , $\$ 11^{\circ}$ inciso VIII e IX) (BRASIL, 2009e); Diretrizes Curriculares Nacionais para o Ensino Fundamental de 9 (nove) anos (Resolução CNE/CEB n 7/2010, no Art. 15, $\$ 2^{\circ} \mathrm{e} \$ 3^{\circ}$ ) (BRASIL, 2010b); Diretrizes Curriculares Nacionais para o Ensino Médio (Parecer CNE/CEB n 5/2011 nas páginas 9, 23, 46; e Resolução CNE/ CEB no 02/2012 no Art. 9', inciso I, alíneas 'c' e 'd'); Diretrizes Curriculares Nacionais 
para a Educação Profissional Técnica de Nivel Médio (Resolução CNE/CEB nº 6/2012, no Princípio XI) (BRASIL, 2012c); Diretrizes Curriculares Nacionais para a Formação Inicial e Continuada dos Profissionais do Magistério da Educação Básica (Parecer CNE/ CP nº 2/2015) (BRASIL, 2015).

\section{Democratização do currículo como um desafio}

\section{para a educação brasileira e para as IES}

As reflexões relacionadas à temática democratização no contexto brasileiro, não somente, mas em muitos momentos, localizam-se em debates a respeito do direito à participação em instâncias decisórias da sociedade. Porém, ao se fazer referência à democratização do currículo é possível além da questão da participação no processo de decisão, também incluir outros elementos situados no cenário educacional que passam a compor as referências desta reflexão.

As diretrizes, a legislação educacional, a proposta curricular dos diversos níveis da educação brasileira e a formação docente inicial e continuada, precisam ser desenvolvidas mantendo entre estes elementos uma coerência, como condição principal da transformação da prática pedagógica e do conteúdo curricular. Porém não é descartada a hipótese, de que mesmo existindo um amplo amparo legal, fruto de lutas por conquistas sociais de combate a desigualdade, uma proposta curricular possa não ser efetivada. Isto pelo fato de que a definição do currículo escolar que será efetivado na prática docente, esta condicionado a uma diversidade de outras influências objetivas e subjetivas, que estão presentes em indivíduos e instituições com poder de decisão em instâncias de preponderância em um processo de efetivação de um conteúdo curricular.

A educação escolar é de forma significativa responsável pela transmissão sistematizada da memória oficial de uma nação. Esta memória, também esta sujeita a ser manipulada por interesses diversos entre eles, o de ressaltar determinados feitos e açố em detrimento de outros; o de silenciar lutas; de ocultar protagonismo, atrocidades, assassinatos, extermínios, crimes contra a humanidade; o de manipular populações, defender a perpetuação de um status quo, etc. Por esta razão a representação e a interpretação histórica é também um campo político de disputa entre os que desejam romper com situações de marginalização e desigualdades históricas e os que desejam manter esta mesma situação. Segundo Teixeira (2008):

Cícero, no De Oratore (55 a.C.), alude a utilidade do relato histórico em sentença memorável e exaustivamente repetida até os nossos dias: á história é testemunha dos séculos, luz da verdade, vida da memória, mestra da vida, mensageira do passado. Menor atenção, porém, foi dedicada pela posteridade à pergunta que fecha a ilustre passagem: 'que voz, se não a do orador, pode torná-la imortal?' (TEIXEIRA, 2008, p. 557)

A partir da inspiração advinda do registro de Teixeira (2008) e das reflexões que este registro provoca interessante pensar a respeito dos desa fios de uma democrestizaça Educação e do professor na democratização do espaço escolar e curricular. Sendo importante lembrar, que não existe neutralidade no currículo escolar, na formação docente, na ação institucional e até mesmo no exercício da atividade docente. Porque, as ausências e permanências neste campo de disputa refletem relações de poder que poderão estar em determinado momento mais distantes ou próximas de uma dimensão político-ideológica pautada na democracia, na observação de direitos humanos, no combate ao racismo, no respeito à diversidade, na democratização da aprendizagem, no fortalecimento da cidadania, etc. A aprovação da Lei 10.639/03, considerada aqui como uma política de promoção da igualdade racial e igualmente, apreciada como parte de um processo de democratização curricular, transforma uma luta social contra a desigualdade em uma orientaç̃o a ser observada no contexto da educação brasileira. A democratização do currículo escolar proposta pela legislação, indica a necessidade do desenvolvimento de uma proposta pedagógica e de uma prática escolar e docente direcionada para uma nova perspectiva de indivíduo e sociedade. E por este motivo, também estará associada a uma concepção de nação e de relação com a diversidade étnico-racial nela explíita.

O Brasil do início dos anos 2000, apresenta como uma de suas características no cenário educacional a presença de ações do Estado em direção da busca de alternativas para o atendimento de algumas demandas educacionais históricas reivindicadas pela sociedade civil organizada, pelas populaçoes marginalizadas e pelos acordos internacionais pautados na educação como um direito de todos e na garantia da observação dos direitos humanos e do combate ao racismo, o preconceito e a discriminação. São os anos nos quais são incorporados à educação brasileira um rol de princípios de valorização d diversidade, de reconhecimento de direitos humanos, de orientação para a garantia do direito a aprendizagem.

A partir do ano de 2004, para atender ao previsto na Lei 10.639/03 é estruturado um percurso formativo no âmbito da legislação educacional com o objetivo de criar as condições para que a prática docente possa adaptar-se ao novo paradigma educacional. O que gera a necessidade de pensar e instituir mecanismos para a efetivação da legislação. Porém, é comum ouvir de professores em ambiente escolar, quando indagados a respeito da implementação da Lei 10.639/03, o argumento de que existe uma carência na formação inicial e continuada com relação a esta temática; por este motivo, examinar os mecanismos instituídos para auxiliar na implementação da Lei 10.639/03 permite a reflexão a respeito de hipóteses de obstáculos ideológicos e estruturais que podem ter se constituído no processo de implementação da legislação.

Como mencionado anteriormente, desde a LDB 9394/96 a formação docente inicial passou a ter como local de referência as IES. Podendo também estas, por meio de parcerias institucionais ou ofertas de cursos de extensão, atuar na formação continuada dos docentes. Assim sendo, a Lei 10.639/03 apresenta as mantenedoras da Educação Básica e as IES o desafio de atuar junto com outros mecanismos sociais, como agentes de promoção da igualdade racial, fornecendo subsídios na formação docente para que a legislação tenha condições de ser efetivada. Entre as estruturas internas das IES definidas na legislacão como elementos de apoio no processo de implementação da Lei 10.639/03, encontra-se os Núcleos de Estudos Afrobrasileiros (NEABs).

\section{NEABs: legislação e estratégia nas IES para}

auxiliar na implementação da lei 10.639/03

Ratts (2009) situa o surgimento dos NEABs no interior das IES no contexto do ovimento negro contemporâneo e os categoriza em sua fase inicial nos anos de 1980 e 1990 como um elemento da face do movimento negro de base acadêmica. Em função das suas características iniciais, os núcleos, reportam aos grupos de estudos e discussão organizados por jovens negros acadêmicos nos anos de 1970. Porém, segundo Ratts (2009), somente nas décadas posteriores serão criados os NEABs tendo em sua maioria dirigentes negros: 
Nos anos 1980 e 1990 foram criados Núcleos de Estudos Afrobrasileiros, com essa denominação ou correlata, voltados para o estudo do racismo e das relaçoes raciaas: CEAB/UCG (1983), NEAB/UFAL (1983), NEAB/UFMA (1985), NEN/UFSC (1986), PENESB/UFF (1995), NEAB UFSCar (1995), E NEAB/UDESC (1995). Estes núcleos, em sua maioria, foram fundados e dirigidos por docentes/pesquisadores(as)/ativistas negros(as) (RATTS, 2009, p. 90).

Os NEABs permaneceram atuantes no interior de algumas universidades fomentando encontros, formação e reflexão; a exemplo, o Núcleo de Consciência Negra da USP (1991) organizado por estudantes e aberto a participação de professores e funcionários. Este Núcleo criou, em 1995, o Comitê de Cotas para Negros na USP, que mesmo não tendo atingido seus objetivos e seus membros sofrido retaliações, fomentaram a reflexão a respeito das cotas e somaram esforços na luta para a adoção de ações afirmativas, que nos anos seguintes foi fortalecida até culminar na aprovação da Lei Federal nº 12.711/2012 (cotas na Educação Superior) (BRASIL, 2012d).

O papel das Instituições de Educação Superior (IES) como agente de promoção da igualdade racial começa a ser delineado por meio de legislações a partir do ano de 2002. Inicialmente a Lei no 10.558 em 13 de novembro de 2002 irá instituir o Programa Diversidade na Universidade (BRASIL, 2002b), que se torna um instrumento a ser usado na articulação e apoio de estratégias contra a exclusão social e a discriminação racial no interior das IES.

A legislação relacionada à promoção da igualdade racial a partir da Lei no $10.558 / 02$ az com que as universidades brasileiras passem a representar um espaço de promoção igualdade racial, contando inclusive com a possibilidade de apoio financeiro como um incentivo a essas instituições para direcionar a formação na Educação Superior (inicial e continuada) bem como, o espaço físico e teórico das IES, para uma atuação no campo da dessimbolização e ressimbolização das relações raciais.

Estes mecanismos legais criados para reverter esta situação de marginalização histórica da população negra e dar visibilidade às contribuições desta população para a sociedade brasileira no contexto social e educacional, além de ser fomentado por pautas do movimento negro brasileiro é um elemento importante no processo de democratização do currículo, bem como, da luta pela promoção da igualdade racial. Justificado pelo fato de que, como afirma Cruz (2005, p. 21), mesmo no século XXI o eurocentrismo histórico e a invisibilidade das contribuiçōes da população negra nas diversas áreas do conhecimento permanece como um elemento presente e ainda não superado na realidade brasileira.

A aprovação da Lei no 10.639 no ano de 2003 (BRASIL, 2003) impulsionou reflexões a respeito do processo de formação docente inicial e continuada, gerando desdobramentos na legislação educacional com o objetivo de garantir o atendimento do previsto na Le 10.639/03. Em função disto em 10 de março de 2004, complementando o previsto na Lei 10.639/03 é promulgado o Parecer CNE/CP n ${ }^{\circ} 03$ de 10 de março de 2004 pelo Conselho Nacional de Educação e este parecer passa a regulamentar as Diretrizes Curriculares Nacionais para Educação das Relações Étnicorraciais e para o Ensino de História e Cultura Afro-brasileira e Africana. No Parecer $\mathrm{CNE} / \mathrm{CP} \mathrm{n}^{\circ} 3$ constam orientações para a definição de ações e projetos que atendam o previsto na Lei 10.639/03; e os Núcleo de Estudos Afro-Brasileiros (NEABs) passam a ser considerados como um elemento de apoio a implementação da Lei 10.639/03 e do próprio Parecer CNE/CP no 3. No parecer belecimentos de Educação Básica em parceria com os NEABs das IES no trabalho com questão étnico-racial no ambiente escolar, como por exemplo, levantamento de dúvidas dificuldades dos professores e medidas para resolvê-las, formação de professores, seleçâo de conteúdos e procedimentos de ensino e aprendizagem, seleção, produção e distribuição de materiais com conhecimentos focados na questão racial, combate a discriminação e ao racismo.

Em 17 de junho de 2004, tendo como fundamentação o Parecer CNE/CP no 03/04 é homologada pelo Ministério da Educação a Resolução CNE/CP n ${ }^{\circ} 1$ de 17 de junho de 2004, que institui as Diretrizes Curriculares Nacionais para a Educação das Relações Étnico-Raciais e para o Ensino de História e Cultura Afro-Brasileira e Africana e apresenta questões a serem observadas pelas instituições de ensino em seus diversos níveis, entre elas, a inclusão "[...] nos conteúdos de disciplinas e atividades curriculares dos cursos que ministram, a Educação das Relações Étnico-Raciais, assim como, o tratamento de questões e temáticas que dizem respeito aos afrodescendentes" (BRASIL, 2004). A Resoluça CNE/ $\mathrm{CP}^{\circ}{ }^{1}$, de 17 de junho de 2004, reconhece a existência dos NEABs e a possibilidade de diálogo deste com os sistemas e estabelecimentos de ensino no processo de elaboração de planos institucionais, pedagógicos e projetos de ensino

Com a promulgação dos instrumentos legais mencionados anteriormente, voltados para a organização da educação das Relações étnico-raciais e a presença da história e cultura afro-brasileira e africana no currículo escolar em seus diversos níveis, o Ministério da Educação (MFC) o Conselho Nacional de Secretários de Educação (CONSED) e a União Nacional dos Dirigentes Municipais de Educação (UNDIME) iniciam uma mobilização a partir do ano de 2007, para a elaboração de uma política educacional nacional expressa em um Plano Nacional de Implementação das Diretrizes Curriculares Nacionais para Educação das Relações Étnicorraciais e para o Ensino de História e Cultura Afro-brasileira e Africana. Com o objetivo de elaborar o Plano foram realizados durante o ano de 2008 seis encontros distribuídos nas cinco regiões brasileiras para diálogo a respeito da temática, denominados Diálogos Regionais e tendo como temática central a implementação da Lei no 10.639/03 e das Diretrizes Curriculares da Educação das Relações Étnico-Raciais.

No ano de 2009 foi aprovado o Plano Nacional de Implementação das Diretrizes Curriculares Nacionais para Educação das Relações Étnicorraciais e para o Ensino de História e Cultura Afro-brasileira e Africana (BRASIL, 2009d). Sendo que no plano e definido as atribuições dos Núcleos de Estudos Afro-Brasileiros (NEABs) ou similares das IES e as estratégias para a implementação e efetivação da Lei 10.639/03, do Parecer $\mathrm{CNE} / \mathrm{CP} n^{\circ}$ 03/04, da Resolução CNE/CP nº 01/04 e da então aprovada Lei 11.645/08 (BRASIL, 2008) que inclui a obrigatoriedade da temática da história e cultura indígena como conteúdo curricular.

Com o Plano Nacional de Implementação das Diretrizes Curriculares Nacionais para Educacão das Relações Etnicorraciais e para o Ensino de História e Cultura Afro-brasileir e Africana, os NEABs passam a ser um espaço estratégico no processo de implementação da Lei 10.639/03 e da legislação promulgada em consequência desta, bem como, espaço de formação, produção de materiais e articulação na luta pela promoção da igualdade racial.

\section{Considerações finais}

O espaço da educação em seus diversos níveis e instâncias de decisão é um campo de disputas, sendo que “[...] nele se dão, continuamente, tensões e disputas internas entre os agentes e grupos, que buscam estabelecer sua dominância ou legitimidade, utilizando-se dos capitais de que dispõem, e de estratégias e práticas que visam a conquistar e manter essa legitimidade" (GONÇALVES, 2014, p. 2). A Lei 10.639/03 está inserida neste contexto de disputas, representando uma luta pelo reconhecimento e legitimidade de uma democracia curricular pautada no reconhecimento da pluralidade e na diversidade brasileira. Porém a contínua luta protagonizada por uma diversidade de segmentos sociais e o movimento 
negro brasileiro pela efetivação desta lei, após 13 anos de promulgação e de um histórico de luta do movimento negro que a antecede, parte do princípio de que:

A declaração e a garantia de um direito tornam-se imprescindíveis no caso de páses como o Brasil, com forte tradição elitista e que tradicionalmente reservam apenas às camadas privilegiadas o acesso a este bem social. Por isso, declarar e assegurar é mais do que uma proclamação solene. Declarar é retirar do esquecimento e proclamar as que não sabem, ou esqueceram, que eles continuam a ser portadores de un direito importante. Disso resulta a necessária cobrança deste direito quando ele não érespeitado (CURY, 2002, p. 259).

As propostas de implementação da Lei 10.639/03 presente na legislação educaciona e posterior a esta lei, coloca as IES, não como o único, mas como um dos elementos centrais e de vital importância neste processo de efetivação da Lei 10.639/03. Com isto, coloca as IES, o sistema educacional, os estabelecimento de ensino e os docentes diante do que Batista (2015) descreveu como "[...] escolha fundamental: ou reforça-se o ciclo do patrimonialismo político e do preconceito social que se arrastam desde o início de uma sociedade ainda sob o signo da escravidão ou procura-se rompê-lo" (BATISTA, 2015, p. 96). A questão crucial é que não existe neutralidade neste processo e as escolhas realizadas indicarão qualé a concepč̃o de indivíduo, sociedade e nação que desejamos pura as futuras gerações e o quanto ela estará próxima do rompimento com as desigualdades sociais e da efetivação da democracia.

\section{Referências}

ALBERTI, Verena; PEREIRA, Amilcar Araujo. Histórias do movimento negro no Brasil: depoimentos ao CPDOC. Rio de Janeiro: Pallas; CPDOC-FGV, 2007.

ASSUNÇÃO, Paulo de. Negócios Jesuíticos: o cotidiano da Administração dos Bens Divinos. São Paulo: Editora da Universidade de São Paulo, 2009.

ATTALI, Jacques. Os judeus, o dinheiro e o mundo. São Paulo: Futura, 2003.

BATISTA, N. C. Políticas públicas de ações afirmativas para a educação superior: o Conselho Universitário como arena de disputas. Aval. Pol. Públ. Educ., Rio de Janeiro, v. 23, n. 86, p. 95-128, jan./mar. 2015

BENTO, Maria Aparecida. Branqueamento e Branquitude no Brasil. In: CARONE, Iray; BENTO Maria Aparecida Silva (Org.). Psicologia social do racismo: estudos sobre branquitude e branquemento no Brasil. Petrópolis, RJ: Vozes, 2002.

BERBEL, Márcia. Escravidão e politica: Brasil e Cuba. São Paulo: HUCITEC/Fapesp, 2010

BRASIL. Municipio da Côrte. Decreto n ${ }^{\circ}$ 1.331-A, de 17 de fevereiro de 1854. Approva o Regulamento d'Estado dos Negocios do Imperio, 1854. Disponível em: <http://www2.camara.leg.br/legin/fed/ decret/1824-1899/decreto-1331-a-17-fevereiro-1854-590146-publicacaooriginal-115292-pe html Acesso em: 20 dez. 2015.

. Decreto nº 58.023, de 21 de março de 1966. Dispõe sôbre a educação cívica em todo o país (a)

. Decreto no 1.904, de 13 de maio de 1996. Programa Nacional de Direitos Humanos (PNDH-1). Institui o Programa Nacional de Direitos Humanos (PNDH). Brasilia, DF: Presidência da República, 996a. Disponivel em: <<http://www. planalto.gov.br/ccivil_03/decreto/d1904.htm>. Acesso em: ago. 2016 . Decreto $\mathrm{n}^{\circ}$ 4.229, de 13 de maio de 2002. Programa Nacional de Direitos Humanos
(PNDH-2). Dispóne sobre o Programa Nacional de Direitos Humanos (PNDH), instituído pelo Decreto no 1.904, de 13 de maio de 1996, e dá outras providências. Brasília, DF: Presidência da República 002a. Disponivel em: <http://www.planalto. gov.br/ccivil_03/decreto/2002/D4229.htm>. Acesso em: 21 ago. 2016.

Decreto $\mathrm{n}^{\circ} 7.037$, de 21 de dezembro de 2009a. Programa Nacional de Direitos Humano (PNDH-3). Aprova o Programa Nacional de Direitos Humanos (PNDH-3) e dá outras providências. Secretaria Especial dos Direitos Humanos da Presidência da República. Brasília, DF: SEDH/PR, 2009. Disponível em: <http://www. planalto.gov.br/ccivil_03/_Ato2007-2010/2009/Decreto/D7037. htm\#art7>. Acesso em: 21 ago. 2016.

Decreto no 6.755 de 29 de janeiro de 2009. Institui a Política Nacional de Formacão de Profissionais do Magistério da Educaç̃o Básica disciplina a atuação da Coordenaç̃̃o de Aperfeiçoamento de Pessoal de Nivel Superior/CAPES no fomento a programas de formação inicial e continuada, e dá outras providências. Braślia, DF: Diário Oficial da República Federativa do Brasil, 30 jan. 2009. p. 1. Disponivel em: <http://www.planalto.gov.br/ccivil_03/_ato2007-2010/2009/decreto/ d6755.htm>. Acesso em: 28 set. 2016.

Decreto $\mathrm{n}^{\circ} 8.752$, de 9 de maio de 2016. Dispõe sobre a Politica Nacional de Formação dos Profissionais da Educacão Básica. Brasília, DF: Ministério da Educacão, 2016. Disponível em http://www.planalto.gov.br/ccivil_03/_Ato2015-2018/2016/Decreto/D8752.htm>. Acesso em: 27 set. 2016

. Lei no 9.394, de 20 de dezembro de 1996. Estabelece as Diretrizes e Bases da educação Nacional. Brasilia, DF: MEC, 1996b. Disponível em: <http://www.planalto.gov.br/ccivil_03/leis/

Lei no $10.558 \mathrm{em} 13$ de novembro de 2002. Cria o Programa Diversidade na Universidad dá outras providências. Brasilia, DF: Presidência da República, 2002b. Disponivel em: <http:/ www.planalto.gov.br/ccivil_03/leis/2002/L10558.htm>. Acesso em: 27 set. 2016.

. Lei $\mathrm{n}^{\circ} 10.639$, de 9 de janeiro de 2003. Estabelece as diretrizes e bases da educacão nacional para incluir no currículo oficial da Rede de Ensino a obrigatoried de da Temética Histórin Cultur Afro-Brasileira. Brasília, DF: Presidência da República, 2003. Disponível em: <http://www. planalto. gov.br/ccivil_03/leis/2003/L10.639.htm>. Acesso em: 28 set. 2016 .

Lei 11.645, de 10 de março de 2008. Altera a Lei no 9.394, de 20 de dezembro de 1996, modificada pela Lei no 10.639, de 9 de janeiro de 2003, que estabelece as diretrizes e bases da educação "Cultura Afro-Brasileira e Indígena". Brasília. DF: Presidência da Reṕblica 2008 Dispońvel em

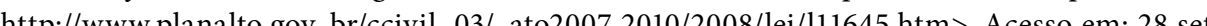

Lei no 12.288 , de 20 de julho de 2010. Estatuto da Igualdade Racial. Brasília, DF: Presidência a República, 2010a. Disponível em: <http://www.planalto.gov.br/ccivil_03/_ato2007-2010/2010/ bi/l12288 htm $>$ Acesso: 26 set. 2016

Lei $\mathrm{n}^{\circ} 12.711$, de 29 de agosto de 2012. Dispõe sobre o ingresso nas universidades federais enas instituiçoes federais de ensino técnico de nivel medio e da outras providencias. Brasilia, DF Presidência da República, 2012d. Disponivel em: <http://www.planalto.gov. br/ccivil_03/_ato20112014/2012/lei/l12711.htm>. Acesso em: 27 set. 2012 .

. Lei no 13.005, de 25 de junho de 2014. Aprova o Plano Nacional de Educação (PNE) e da outras providências. Braślia DF. Diário Oficial da República Federativa do Brasil 26 jun. 2014. Edição Extra, p. 1. Disponivel em: <http://www.planalto.gov.br/ccivil_03/_ato2011-2014/2014/lei/ 113005.htm>. Acesso em: 24 jul. 2016.

Parecer CNE $/ \mathrm{CP} \mathrm{n}^{\circ} 5$, de 13 de dezembro de 2005. Diretrizes Curriculares Nacionais para Curso de Pedagogia. Brasilia, DF: MEC, 2005. Disponível em: <http://portal mec govbr/cne/ o Curso de Pedagogia. Brasilia, DF: MEC, 2005. Dispon
arquivos/pdf/pcp05_05.pdf>. Acesso em: 29 set. 2016.

Ministério da Educação. Parecer CNE/CEB nº 5, de 4 de maio de 2011. Diretrizes Curriculares Nacionais para o Ensino Médio. Brasília, DF: Câmara de Educação Básica, 2012a. Disponível m: <http://pactoensinomedio.mec.gov.br/images/pdf/pceb005_11.pdf >. Acesso em: 24 ago. 2016.

. Parecer CNE/CP no 2/2015, de $1^{\circ}$ de julho de 2015. Define as Diretrizes Curriculare Nacionais para a formação inicial em nivel superior (cursos de licenciatura, cursos de formaçăo 
pedagógica para graduados e cursos de segunda licenciatura) e para a formação continuada. Brasilla DF: Ministerio da Educaçáo; Conselho Nacional de Educaçăo; Conselho Pleno, 2015. Disponíve em: <http://portal.mec.gov.br/index.php?option=con_docman\&view=downoadzallas=17719-res -cne-cp-002-03072015\&category_slug=julho-2015-pdf\&Itemid=30192>. Acesso em: 25 set. 2016.

.Plano Nacional de Implementacão das Diretrizes Curriculares Nacionais para a Educação das Relações Etnicorracial e para o Ensino de História e Cultura Afrobrasileira e Africana. Brasília, DF: MEC/SECAD, 2009d. Disponível em: <http://portal.mec.gov.br/index. php?option=com_docman\&view=download\&alias=1852-diretrizes-curriculares-pdf\&Itemid=30192>. Acesso em: 20 set. 2016.

. Projeto de Lei no 1.239 de 1995, de 21 de novembro de 1995. Garante a reparação com indenização para os descendentes dos escravos no Brasil. Brasília, DF: Câmera dos Deputados, 1995. Disponível em: $<$ http://www.camara.gov.br/proposicoesWeb/ fichadetramitacao?idProposicao $=16454>$. Acesso em: 29 set. 2016

. Projeto de Lei $\mathrm{n}^{\circ} 4567$, de 28 de maio de 1998. Cria o Fundo Nacional para o Desenvolvimento de Ações Afirmativas (FNDAA). Brasília, DF: Câmera dos Deputados, 1998. Disponível em: $\langle$ http://www.camara.gov.br/proposicoesWeb/fichadetramitacao?idProposicao $=25679>$. Acess em: 25 set. 2016

. Projeto de lei n $\mathrm{n}^{\circ} .567$ de 1998. Cria o Fundo Nacional para o Desenvolvimento de Açồe Afirmativas (FNDAA). Brasilia, DF: Câmera dos Deputados, 1998. Disponivel em: <http://www camara.gov.br/proposicoesWeb/prop_mostrarintegra;jessionid=86BF57878FD54256D8C1C6047F401EDF.proposicoesWebl?codteor=1128983\&filename=Avulso+-PL+4567/1998>. Acesso em: 28 set. 2016

Projeto de Lei nº 259, de 11 de março de 1999. Dispõe sobre a obrigatoriedade da inclusão, no currículo oficial da Rede de Ensino, da temática Historia e Cultura Afro-Brasileira e dá outras providências. Brasilia, DF: Câmara dos Deputados, 1999. Disponível em: <http://www.camara.gov. br/ proposicoesWeb/fichadetramitacao?idProposicao=15223>. Acesso em: 28 set. 2016.

. Resolução nº 2, de 28 de maio de 2009. Fixa as Diretrizes Nacionais para os Planos de Carreira . http://portal mec govbr/dmdocuments/resolucao_cne_ceb002 2009 pdf>. Acesso em: 26 set. 2016 .

Resolução CNE/CEB n 5, de 17 de dezembro de 2009. Fixa as Diretrizes Curriculare Nacionais para a Educação Infantil. Brasilia, DF: Ministério da Educação; Conselho Nacional de Educação; Câmara de Educação Básica, 2009e. Disponivel em: <http://portal.mec.gov.br/index php?option=com_docman\&view=download\&alias=229

. Resolução CNE/CEB n ${ }^{\circ}$ 7, de 14 de dezembro de 2010. Fixa Diretrizes Curriculares Nacionais para o Ensino Fundamental de 9 (nove) anos. Brasilia, D. Ministêto da Educaçáa; Consell Nacional de Educação; Câmara de Educação Básica, 2010b. Disponível em: <http://portal.mec.gov. br/dmdocuments/rceb007_10.pdf>. Acesso em: 26 set. 2016.

. Resolução CNE/CEB nº 2, de 30 de janeiro de 2012. Define Diretrizes Curriculares Nacionais para o Ensino Médio. Brasilia, DF: Ministério da Educação; Conselho Nacional de Educação Câmara de Educação Básica, 2012b. Disponível em: <http://pactoensinomedio.mec.gov.br/images/ pdf/resolucao_ceb_002_30012012.pdf $>$. Acesso em: 27 set. 2016.

. Resolução $\mathrm{CNE} / \mathrm{CEB} \mathrm{n}^{\circ} 6$, de 20 de setembro de 2012. Define Diretrizes Curriculares Nacionais para a Educação Profissional Técnica de Nivel Médio. Brasília, DF: Ministério da Educação, 2012 Disponível em: $<$ http://portal.mec. gov.br/index.php?option=com_docman\& \&view=downlond Dlins=11663-rceb006-12 pdf\&-Itemid=30192 $>$ Acesso em: 26 set. 2016 .

. Resolução CNE/CP no 01 de 17 de junho de 2004. Institui as Diretrizes Curriculares Nacionais para a Educação das relaçôes étnico-raciais e para o ensino de história e cultura afro-brasileira
e africana. Relatora: Petronilha Beatriz Gonçalves. Ministério da Educação. Brasília, DF: MEC, 2004.

CASTRO, Therezinha. José de Bonifácio e a Unidade Nacional. Rio de Janeiro: Biblioteca do Exécito, 1984

CAVALLEIRO, E. Valores civilizatórios: dimensões históricas para uma educação anti-racista. Ministério da Educacão: Secretaria da Educção Continuada. Alfabetização e Diversidade. Orientaçôss e Ações para Educação das Relações Étnico-Raciais. Brasília, DF: SECAD, 2006.
CURY, C. R. J. Direito à educação: direito à igualdade, direito à diferença. Cadernos de Pesquisa, São Paulo, n. 116, p. 245-262, jul. 2002.

FERNANDES, Florestan; FERNANDES, Anamélia Lima Rocha. Politicas de cotas raciais para o ingresso em instituiçóes públicas de ensino superior no Brasil: ausência de política pública. Brasília DF: Biblioteca Digital da Câmara do Deputados, 2010. Disponivel em: <http://bd.camara.leg.br/ bd/bitstream/handle/bdcamara/5564/politica_cotas_raciais_fernandes.pdf?sequence $=5>$. Acesso em: 25 set. 2016.

GONÇALVES, N. G. Indissociabilidade entre Ensino, Pesquisa e Extensão: um princípio necessário. Curitiba: Mimeo, 2014.

GOMES, N. L. Diversidade étnico-racial, inclusão e equidade na educação brasileira: desafios, seer.ufrgs.br/rbpae/article/viewFile/19971/11602>. Acesso em: 15 jan. 2016.

GRIN, Monica. Ambiguidades do multiculturalismo no Brasil: dílogos entre negros e judeus. Revista WebMosaica, Porto Alegre, v. 1, n. 1, jan./jun. 2009. Disponível em: <http://www.seer.ufrgs. br/webmosaica/article/view/9769>. Acesso em: 22 dez. 2015.

MALHEIRO, Agostinho Marques Perdigão. A escravidão no Brasil: Ensaio Histórico-JurídicoSocial. Parte 3: Africanos. Rio de Janeiro: Typographia Nacional, 1867. Disponível em: <http:// www2 senado.leg br/bdsf/item/id/174437>. Acesso em: 24 set. 2016.

MONSMA, Karl Martin. A reprodução do racismo: fazendeiros, negros e imigrantes no oeste paulista, 1880-1914. São Carlos: EdUFSCar, 2016.

MOORE, Carlos. Racismo e Sociedade: novas bases epistemológicas para entender o racismo. Belo Horizonte: Nandyala, 2012.

ONU. Organização das Nações Unidas. Declaração e Plano de Ação de Durban/ONU. III Confeência Mundial de combate ao Racismo, Discriminação Racial, Xenofobia e Intolerância Correlata. Durban: ONU, 2001. Disponível em: <http://www.unfpa.org.br/Arquivos/declaracao_durban.pdf>. Acesso em: 28 set. 2016.

PEREIRA, Amauri Mendes; SILVA, Joselina da (Org.). Movimento Negro Brasileiro: escritos sobre os sentidos de democracia e justiça social no Brasil. Belo Horizonte: Nandyala, 2009.

PEREIRA, Amilcar Araujo. Relações raciais e a constituição do Movimento Negro Contemporâneo no Brasil. Rio de Janeiro: Pallas; FAPERJ, 2013.

RATTS, Alex. Encruzilhadas por todo percurso: individualidade e coletividade no Movimento

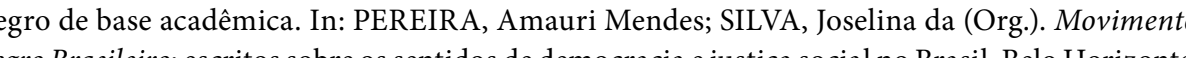
egro Brasileiro: escritos sobre os sentidos de democracia e justiça social no Brasil. Belo Horizonte

EIS, José Carlos. As identidades do Brasil 1: de Varnhagen a FHC. Rio de Janeiro: Editora FGV, 2007. REIS, João José. Rebelião Escrava no Brasil: história do levante do Malês em 1835. São Paulo: Editora Brasiliense, 1986.

SANTOS, Ivair Augusto Alves dos. Direitos humanos e as práticas de racismo. Brasília, DF: Edições Câmara, 2015.

SILVA, Joremir Machado da. História regional da infâmia: o destino dos negros farrapos e outras iniquidades brasileiras (ou como se produzem os imaginários). Porto Alegre: L\&PM Editores, 2010. SILVA, Silvio José Albuquerque e. As Nações Unidas e a luta internacional contra o racismo. Braślia, DF: Fundação Alexandre de Gusmão, 2011.

TAUNAY, Carlos Augusto. Manual do Agricultor Brasileiro. Organização Rafael de Bivar Marquese. São Paulo: Companhia das Letras, 2001.

TEIXEIRA, Felipe Charbel. Uma construçăo de fatos e palavras. Cicero e a concepçăo retơrica da historia. Revista Varia Historia, Belo Horizonte, v. 24, n. 40, p. 551-568, jul./dez. 2008. Disponive em: <http://www.scielo.br/scielo.php?script=sci_arttext\&pid=S0104-87752008000200014>. Acesso em: 21 set. 
